\title{
INTERCOMMUNITY SPORT EVENTS: VEHICLES AND CATALYSTS FOR SOCIAL CAPITAL IN DIVIDED SOCIETIES
}

\author{
NICO SCHULENKORF, ALANA THOMSON, and KATIE SCHLENKER
}

School of Leisure, Sport and Tourism, University of Technology, Sydney (UTS), Sydney, Australia

\begin{abstract}
Sport events are believed to promote dialogue, integration, and peaceful understanding among disparate groups, even when other forms of negotiation have not been successful. However, the social outcomes from sport events are largely anecdotal and there is a need to empirically examine the active engagement of groups with "others" in participatory sport event projects. This article investigates the potential of an intercommunity sport event in contributing to intergroup development and social capital building in the ethnically divided Sri Lanka. It follows an interpretive mode of inquiry where findings are derived from the analysis of 35 in-depth interviews with Sinhalese, Tamil, Muslim, and international event stakeholders. By providing evidence of the varying sociocultural experiences at the event, this article discusses the event's impact on intergroup relations and its influence on the stock of social capital available to communities. Findings can assist governments, policy makers, and nongovernmental organizations (NGOs) in advancing policies and practical measures that build on events as vehicles and catalysts for enhanced intergroup relations and the creation of social capital.
\end{abstract}

Key words: Sport event experiences; Community participation; Intergroup relations; Social capital; Strategic management

\section{Introduction}

People from all over the world love to play, attend, watch, listen to, talk about, experience, and even feel sport at any level of performance. Local community sport events are attended by friends and family week after week, and national and international sporting competitions allow fans to follow sport teams all around the globe to loyally support "their" squad. At the 2006 Football World Cup, for example, tens of thousands of Australian and Japanese supporters traveled for up to 30 hours to cheer on their teams in Germany. Apart from the usual rivalries, it was reported that fans of different nations celebrated together, before, during, and after the matches (Ohmann, Jones, \& Wilkes, 2006; Smith-Spark, 2006). For such reasons, sport has been described as a language that

Address correspondence to Dr. Nico Schulenkorf, School of Leisure, Sport and Tourism, University of Technology, Sydney (UTS), Sydney, Australia, P.O. Box 222, Lindfield 2070, NSW, Australia. Tel: +61 295145368; Fax: +61 295145195; E-mail: nico.schulenkorf@uts.edu.au 
all people in the world speak and understand and, in turn, has the ability to combine and unite groups emotionally (Dyreson, 2003).

Better publicized sport events, such as World Cups or the Olympic Games, have demonstrated this social power of sport. For example, North and South Korea marching under one flag at the 2000 Sydney Olympics, or Cathy Freeman's symbolic lighting of the Olympic torch, represent diverse communities standing and feeling together as one. However, the social outcomes from such symbolic demonstrations are largely anecdotal. It is argued that for disparate communities to experience lasting benefits from sport events there is the need to move beyond symbolism and anecdotes. Active participation with "others" is needed to experience firsthand the power of sport and sport events to contribute to social development (Coalter, 2007; Sugden, 2006). This article provides an empirical investigation of an intercommunity sport event as a strategic tool for reducing social barriers and creating social capital within a divided society. The findings of this research will assist governments, policy makers, and nongovernmental organizations (NGOs) in advancing policies and practical measures that build on sport events as vehicles and catalysts for enhanced intergroup relations and social capital building.

\section{Literature Review}

The literature underpinning this study combines two interrelated areas. First, the social impacts and outcomes of sport events are presented, which includes both the potential of sport events and/or projects to act as a positive force for intercommunity development and the potential of sport events to negatively impact on intergroup relations. Second, the link between sport event experiences, active participation, and social capital is discussed. The two areas of literature provide the theoretical background to the empirical investigation conducted for this study.

\section{Social Impacts and Outcomes of Sport Events}

In 1896, Baron Pierre de Coubertin established the Modern Olympics with the belief that sport events brought people together, and in doing so contributed to a better understanding between peo- ples and nations (Müller \& Gerling, 2006). The universal appeal of sports has also been thought to play a role in the construction, reproduction, and/ or consolidation of social identities in politically, socially, or ethnically divided societies (Schulenkorf, 2010b; Sugden, 2006). For such reasons, governments all over the world have used sport events to capitalize on the pride and unity often generated, to create or advance a shared sense of national purpose, pride, and identity (Jarvie, 2003; Nauright, 1997; Vinoker, 1988).

Anecdotal discussions highlight the interconnection between politics and sport events in regards to the building of nationalism and national consciousness; the creation of national identity and patriotism; and the process of reconciliation (Jarvie, 2003; Maguire, 2002). The building of nationalism, for example, is illustrated by the 1936 Nazi-Olympics in Berlin, which the Hitler regime intended to use as a medium to showcase the Arian race and the Germanic nations as the dominant world power. The use of sport events in creating national identity and patriotism is reflected in the 1980s policy of the African National Congress (ANC) in South Africa, which was "One Can Not Play Normal Sport in an Abnormal Society." When the apartheid regime had finally come to an end, President Mandela argued that sport had become part of the new glue that held the nation together (Jarvie, 2003; Jarvie \& Reid, 1999). Later, in 1995, Mandela wore a Springbok cap and shirt following the country's victory in the Rugby World Cup, and symbolically demonstrated the need for the new "Rainbow Nation" to reconcile by working together and respecting each other (Maguire, 2002).

These anecdotes suggest that sport events are able to promote dialogue, integration, and peaceful understanding among groups. However, empirical evidence that confirms or disproves the power of intercommunity sport events in overcoming social and cultural divides, and therefore impacting on the stock of social capital within and between communities, remains scarce (Chalip, 2006; Kellett, Hede, \& Chalip, 2008). The belief that sport events can contribute to social development by creating social capital and social change stems largely from evaluations of ongoing sport programs in the developing world. Here, different "melting pot" de- 
velopment programs have proven to be successful in promoting longer term cross-cultural understanding and "normalizing" in deeply divided societies such as: Israel (Stidder \& Haasner, 2007; Sugden, 2006); Bosnia/Herzegovina (Gasser \& Levinsen, 2004, 2006); Sierra Leone (Lea-Howarth, 2006); Liberia (Armstrong, 2004); South Africa (Guelke \& Sugden, 2000; Höglund \& Sundberg, 2008); and Northern Ireland (Bairner \& Darby, 2000; Sugden, 1991).

In these examples it has been shown that regularly scheduled sport programs can contribute to people regaining, step by step, a sense of security and confidence when approaching new people, groups, and even politically opposed communities. Active involvement and participation in sports can further lead to skill development, cultural learning, and overall community empowerment (Lawson, 2005; Skinner, Zakus, \& Cowell, 2008). However, in contrast to sport programs, which are regularly scheduled activities that take place over a certain length of time, sport events are seen as short-term intensive activities lasting only a few days. The contribution of sport events to intergroup development and their role in contributing to social capital still needs to be examined.

Contrary to the social benefits documented in the literature, there is a body of literature that highlights the potential negative impacts of sport programs and events, putting forth the argument that such initiatives also have the capacity to worsen intergroup relations (Armstrong \& Giulianotti, 2001; Dimeo, 2001; Higham, 1999; Sack \& Suster, 2000). Negative outcomes arise as a result of several inherent characteristics of sport that reflect the dynamics of broader society, which need to be considered by organizers and communities during the planning and management of intercommunity sport events (Hargreaves, 2000).

First, it is suggested that the competitive nature and rivalry at sport events, with an emphasis on winners and losers (Hargreaves, 2000; Torkildsen, 2000), may lead to negative social impacts such as hooliganism, vandalism, or stampedes (Bishop \& Jaworski, 2003; Griggs, 2004; Sack \& Suster, 2000; Soutar \& McLeod, 1993). Second, several authors have identified an increase in antisocial behavior, criminal activity, violence, and arrests during the period of sport events (Armstrong \&
Giulianotti, 2001; Hall, Selwood, \& McKewon, 1995; Higham, 1999; Sack \& Suster, 2000). Such antisocial behavior may lead to a reiteration or reemergence of historical and prejudicial stereotypes (Dimeo \& Kay, 2004), which are capable of worsening already strained intergroup relations (Dimeo, 2001; Hay, 2001). Thomas and Dyall (1999) even suggest that sport performances are often interpreted by those who watch or participate in them, in ways that dramatize ongoing cultural and political issues.

For these reasons, professional sport events are often considered an ineffective means for establishing or rebuilding any lasting sense of community. The potential for negative outcomes may unintentionally serve as a platform for worsening intergroup relations and contribute to a divide between sportspeople, residents, and interest groups (Hargreaves, 2000; Ingham \& McDonald, 2003; Smith \& Ingham, 2003; Thomson, Darcy, \& Pearce, 2010).

\section{Sport Event Experiences, Active Participation, and Social Capital Building}

In order to utilize sport events as vehicles and catalysts for intergroup development and social capital building, community participation must underpin the event strategies and management (Atkinson, 1991; Brown, Brown, Jackson, Sellers, \& Manuel, 2003; Schulenkorf, 2009, 2010a; United Nations, 2006). The United Nations (cited in Midgley, 1986) defines community participation as "the creation of opportunities to enable all members of a community and the larger society to actively contribute to and influence the development process and to share equitably in the fruits of development" (p. 24). Fundamental to the ideal of community participation is an emphasis on development, which is initiated within communities, taking a bottom-up approach and therefore incorporating a relevance to those affected (Getz \& Frisby, 1988; Kelly, 2002; Quinn, 1999; Reid, 2006). This approach has a greater likelihood of providing an innate sense of cultural relevance, self-determination, sense of belonging for the participants, and better achievement of outcomes (Atkinson, 1991; Thomson et al., 2010).

Recently, research has suggested that sport 
events and sport development projects can have an impact on the stock of social capital available to communities (Misener \& Mason, 2006; Nicholson \& Hoye, 2008; Skinner et al., 2008). Social capital is defined by Baum and his colleagues (cited in Australian Bureau of Statistics, 2002) as "the building of healthy communities through collective, mutually beneficial interactions and accomplishments, particularly those demonstrated through social and civic participation" (p. 3). The central elements for social capital are trust, networks, and reciprocity (Putnam, 1993, 2000, 2003), which are considered as "the oil that lubricates social processes" aimed at positive community development (Kilpatrick, 1999, p. 123).

Trust is described as "the expectation that arises within a community of regular, honest and cooperative behavior, based on commonly shared norms, on the part of other members of that community" (Fukuyama, 1995, p. 26). In intergroup settings, particularly when cultural elements and differing norms and values are involved, trust serves as the foundation for meaningful communication and understanding. According to Putnam (1993, 2000, 2003), three types of trust are important for the creation of social capital: personalized trust, generalized trust, and institutionalized trust. Personalized trust describes experiences on an individual level; this is referred to as "bonding" with well-known people. Generalized trust expands to other groups at an event and is referred to as the "bridging" element of social capital. Institutionalized trust links to the confidence in external parties involved in the organizing of sport events, which is referred to as "linking" social capital (Woolcock, 2001).

Once trust is built, social networks can be created. Networks are the voluntary interlocking of relationships between individuals and groups, and include newly established or fostered contacts, ties, group attachment, or friendship circles. According to Stone (2001), networks are the "structural" elements of social capital. Through participation at sport events, people have the opportunity to build networks on both the personal and professional levels. From within these networks a process of exchange occurs; those interactions are referred to as reciprocity (Stone, 2001). Putnam (2000) explains the concept as "I'll do this for you now, in the expectation that you (or perhaps someone else) will return the favor" (p. 20). Reciprocal acts facilitate access to resources at an individual and collective level, and within a social network. For instance, at a sport event people can gain access to physical resources by borrowing from each other or receiving donated equipment.

While participation in sports has long been considered to build character, teach values, encourage healthy competition, and promote intergroup friendship, there is little empirical evidence of intercommunity sport events and their wider social role (Chalip, 2006). Therefore, this study answers a call for evidence on the effectiveness of sport events in creating social experiences and facilitating the development of social capital. The study empirically examines participation at an intercommunity sport event and whether this can contribute to breaking down social barriers between disparate groups. Using Sri Lanka as a case study, the social and cultural experiences of various stakeholders in the 1st International Run for Peace are analyzed and discussed.

\section{Method}

\section{Context and Setting}

Intergroup relations within multiethnic Sri Lanka have been fraught with difficulties for several decades. The country's Tamil minority has been anxious with the country's unitary form of government, believing that the Sinhalese majority would abuse Tamil rights (Dunung, 1995). In the 1970s the Tamils began to rebel for their religious and cultural identity and started to seek an independent state Tamil Eelam by force. Under the leadership of Velupillai Prabhakaran the Liberation Tigers of Tamil Eelam (LTTE or Tamil Tigers) were formed to fight for self-sovereignty in the northeastern regions of Sri Lanka, which are considered the areas of traditional Tamil settlement. Seeing themselves as the acting representative of the Tamil people, the LTTE's violent demands culminated in a civil war that lasted from 1983 to 2002 and resulted in over 70,000 deaths (Bilger, 2006). In northeastern Sri Lanka, the LTTE managed to establish a de facto state with its own military, police, schools, laws, and courts. In 2002, the Government of Sri Lanka and the 
LTTE finally agreed to commit to a peace process. While the LTTE withdrew from active peace talks after six rounds in April 2003, a cease-fire agreement remained in place until January 2008, when Sri Lanka returned to open civil war. Fourteen months later, after considerable military victories and the regaining of valuable territory from the LTTE in northeastern Sri Lanka, the Government was able to announce victory over the Tamil Tigers and an end to the civil war in May 2009.

Against the background of a deeply divided society, research for this study was conducted in western Sri Lanka from January until April 2007. At that point in time, the LTTE controlled $15 \%$ of the island and claimed another $20 \%$ as their traditional homeland. Intergroup relations among Sri Lanka's ethnic groups were deeply shattered and opportunities for positive intergroup contact were scarce.

\section{The Event}

In an attempt to contribute to positive contact, appeasement, and reconciliation between ethnic groups on a community level, the NGO Asian German Sports Exchange Program (A.G.S.E.P.) has been organizing intercommunity sport events under a "Games for Peace" theme since 2002. These sport events bring Sinhalese, Tamil, Muslim, and international sportspeople together in a leisure environment free of sociopolitical constraints, and therefore conducive to building social capital. With the help of the local communities and international volunteers, A.G.S.E.P.'s vision is "to contribute to the reestablishment of peace in Sri Lanka," with a mission to "popularize social values such as respect, courage, and commitment through sport events" (A.G.S.E.P. website, 2005).

This study focuses on the social and cultural event experiences resulting from people's involvement in the 1st International Run for Peace (IR4P), held on October 1, 2006 in Sri Lanka's capital Colombo. The IR4P followed an earlier A.G.S.E.P. initiative, the National Run for Peace (NR4P), staged in 2004. The NR4P focused at a domestic level, bringing together the different ethnic communities from 12 Sri Lankan districts to run from their home towns to reach the Bogambara stadium in the centrally located city of
Kandy. The IR4P took an international focus. While the local communities were in charge of the design and the marketing of the event to their respective groups, A.G.S.E.P. arranged official approval and support from the Government and Sport Councils, provided the transport for participants from rural areas, and organized event experts and social workers for conducting and supervising the event. Security personnel and medical staff from the local community hospital were also volunteering and present on site.

The IR4P provided a day of celebration, spectacle, and color for 800 national and international participants and several thousand spectators. The IR4P featured three categories. First, a competitive 21-kilometer half-marathon was staged for both male and female athletes. Second, a 10-kilometer "minimarathon" was offered to participants and sports groups who wanted to get some physical activity. Third, a symbolic "peace move" of 5 kilometers was also offered to encourage participation by people of different fitness levels and age groups, who wanted to support the event theme of peace.

One of the unique features of this sport event was the participation and spectating across age, gender, social class, and ethnic/national background. The run started at Colombo's Independence Square and passed through three city districts of very different socioeconomic status: the upperclass Colombo 7 quarter; the slums of Maradana; and the middle-class Kolpitiya district. The run finished at the Colombo Race Course Grounds, where a multicultural music festival was conducted as part of the after-event celebrations. In an awards ceremony, groups were awarded for their valued participation, performance, social contribution, and personal commitment, rather than identifying winners and losers. This was in line with A.G.S.E.P's "no-one loses" philosophy, which put a focus on the social and integrative character of the sport event with its supporting cultural performances, rather than on the actual result of the sport events.

\section{Research Design}

The interpretive paradigm that underpins this study acknowledges that research questions and 
data emerge through a process of induction (Crotty, 1998; Glesne, 1999; Neuman, 2003). That is, the researchers construct and reconstruct meaning in relation to the evolving research questions and the experiences of the participants related to the phenomenon under inquiry (Denzin \& Lincoln, 2005). According to Myers (1997), interpretive studies aim to understand the context of a phenomenon through the meanings that people assign to it. Therefore, the significant elements of the participant's experiences, the study findings, inform the analysis process through coding, themes, and pattern development.

Semistructured in-depth interviews were used to find out in detail about people's sport event experiences. This method was chosen because, according to Hoepfl (1997), in-depth interviews are the most promising method to find out the "real" about contemporary cases and phenomena. In line with the in-depth approach to research, purposeful sampling was applied, as it allows researchers to choose different participants who suit their research subject (Denzin \& Lincoln, 2005; Minichiello, Aroni, Timewell, \& Alexander, 1995; Neuman, 2003). Thus, the integration of voices from all groups that were impacted by sport events could be ensured, which contributed to a holistic and realistic picture of the case.

Key individuals from the main sport event stakeholder groups and from the participating communities were identified for the initial round of interviews. These included community members, event organizers, participants, spectators, sponsors, media, and government representatives. Further interview respondents were accessed through the use of snowball sampling. The combination of community representatives previously known by A.G.S.E.P. and the snowballing method resulted in the lead researcher getting access to a wide spectrum of interviewees, ranging from local fishermen to high profile Members of Parliament. In total, 35 semistructured interviews were conducted between January and April 2007 (see Table 1). They ran for between 35 and 120 minutes each and included questions on the sociocultural impacts experienced and/or witnessed at the IR4P event; and how the event impacted on people's social identities, their sense of belonging, and overall intergroup relations. In cases where the participants' English proficiency did not allow adequate responses, they were assisted by a local Sinhala- and Tamil-speaking interpreter. To guarantee a confidential yet personal presentation of findings, research participants were given pseudonyms.

The computer software used to support the data analysis was NVivo 7, which assisted the researchers in storing, integrating, indexing, and coding the large amount of information collected. Within NVivo, the processes of open and axial coding (see Willis, 2006) are reflected in the creation of free and tree nodes. While free nodes can be described as containers for storing data that "do not assume relationships with other concepts" (Beazley \& Richards, 2000, p. 25), tree nodes are those that allow for hierarchical organization into themes and subthemes. Tree nodes are therefore useful for axial coding and the reorganization of existing free nodes. During the data analysis process both free nodes and tree nodes were used. This resulted in a better understanding of relationships of the data and structures of emerging arguments, and allowed for the coding and reconceptualizing of data into seven themes of experience.

\section{Findings}

The sociocultural experiences of participants in the IR4P were analyzed using an inductive approach, from which emerged seven distinct but interrelated themes. Five themes were considered to contribute to positive social capital building and a reduction of ethnic barriers. Two themes were found to limit opportunities for social capital building, and therefore impact negatively on interpersonal and intergroup relations (see Table 2).

The seven identified themes will be presented next, drawing on representative comments from interview respondents.

\section{Positive Sociocultural Experiences}

Socializing. The category of Socializing includes elements of fun and entertainment; inclusive interaction and shared experiences; and the pride of having actively and creatively contributed to development efforts.

Participation in the IR4P resulted in fun and entertainment for sportspeople, spectators, event 
Table 1

Overview of Interview Respondents

\begin{tabular}{lrl}
\hline Event Stakeholder Type & No. & \multicolumn{1}{c}{ Ethnic Background } \\
\hline Event organizers & 5 & 3 European, 1 Sinhalese, 1 Tamil \\
Volunteers & 4 & 3 European, 1 Muslim \\
Event participants & 4 & 3 Sinhalese, 1 European \\
Event epectators & 4 & 2 European, 1 Sinhalese, 1 Tamil \\
Sinhalese community & 5 & 5 Sinhalese \\
Tamil community & 2 & 2 Tamil \\
Muslim community & 2 & 2 Muslim \\
Government ministries & 2 & 2 Sinhalese \\
LTTE official & 1 & 1 Tamil \\
Sport associations & 2 & 2 Sinhalese \\
Aid organization & 1 & 1 Sinhalese \\
Media & 2 & 1 Sinhalese, 1 Muslim \\
Sponsor & 1 & 1 Sinhalese \\
Total & 35 & 17 Sinhalese, 5 Tamil, 4 Muslim, 9 European \\
\hline
\end{tabular}

organizers, and the local communities. Chulo, a local aid worker, reported that during the IR4P people along the course were "supporting, cheering, celebrating all the time." The open and welcoming character of the sport event led to socializing opportunities for spectators and participants alike. An example of the relaxed social atmosphere among spectators and athletes was the spontaneous celebration of "The Mexican Wave" at the end of the event. Kevin, a former staff member of the Ministry of Sports, praised this symbolic gesture, stating that "when they finished the race and started the wave, it was a good ceremony for the people."

Shawn, a participant in the IR4P, described the integrative cooperation and joint participation at the inter-community sport events as a valuable sociocultural impact which led to positive long-term memories. He said: "You see even now-half a year after the event-people still wear their shirts with 'Run for Peace.' So it is really something that they kept in their hearts and minds for a long time, because they still like to wear it and remember the day." Shawn's example shows that even months after the IR4P people were proud of their active contribution to the intercommunity sport event and enjoyed remembering the peace run as a joint celebration of all Sri Lankan communities.

Trust. The category of Trust includes the elements of intercommunity trust and confidence,

Table 2

Sociocultural Experiences Resulting From the IR4P Sport Event

Theme

Social Experiences

Socializing

Trust

Reciprocity and solidarity

Contact and networks

Learning and development

Attitudes
Fun and entertainment; Inclusive interaction; Shared experiences; Active contribution to development

Rise in intercommunity confidence and belief; Increase in comfort levels; Increase in perceived safety

Intergroup cooperation; Physical support; Emotional support

Individual friendships (bonding); Group contacts and networking (bridging); Business relationships (linking)

Management skills; Sport techniques; Intercultural learning and expansion of perspectives

Differences in affection and enthusiasm; Differences in activity and engagement; Antisocial behavior 
increase in perceived safety, and increase in intergroup comfort levels. Comments made by respondents revealed that for the creation of trust, three elements were of central importance. First, the good reputation of the island-wide known event organizer A.G.S.E.P.; second, symbolic factors such as themes and logos; and third, the supportive nature of key stakeholders.

The acceptance and awareness of A.G.S.E.P. by local communities has constantly improved over the years, and its good reputation as an international yet locally grounded NGO in Sri Lanka has grown. Respondents perceived A.G.S.E.P. as an event organizer that can be trusted. Kappa, for example, stated that "with A.G.S.E.P. as a supporter or expert, people expect a better organized and better managed event of great quality. Simply because that name is on the board." Another reason for A.G.S.E.P.'s acceptance by all communities is their inclusive sport event campaign "Games for Peace" and their politically neutral logo. Ranil stated that A.G.S.E.P. decided to purposely use slogans that focus solely on the impartial sport factor in intergroup relations:

Our logo says "Connecting Sportspeople," which is a very neutral statement. It does not give any ideas or links towards any political affiliation or philosophical direction, we are just connecting sportspeople. There are a boy and a girl, another boy and a girl, and we try to put a ball in between them and try to make people interact through the medium of sport. And that's it.

A trustful organizer increases feelings of safety and comfort. According to media representative Andy, the supporting stakeholders also played a key role in creating feelings of confidence and safety among participants:

It was a very safe event! We took the security's advice and didn't have any problem. You get the fullest support from all the authorities, security, police, army, and everything. And because of the fullest support it was a $100 \%$ secure event.

However, a safe and secure intercommunity sport event does not automatically generate full trust among ethnic groups that have been engaged in civil war for over 25 years. Government representative Jayo explained that "there was some kind of a trust. I don't say it's $100 \%$.... That's why I said it's more or less a confidence building or trust building exercise."

Reciprocity and Solidarity. The category of Reciprocity and Solidarity includes elements of helpful intergroup cooperation, and physical as well as emotional support at the sport events. Feelings of intergroup camaraderie existed around the sport event, which became obvious through the many small gestures and signs of goodwill. Organizer Didi highlighted this through the comment:

The participants who came and took part in the IR4P, they came from drastically different ethnic backgrounds.... We noticed that the support for example towards the poorer participants was shown by the more affluent, richer participants in the sense that they have also supported them with materials, with T-shirts, sometimes also with shoes. Because we had runners that didn't even have shoes!

While the generous sharing of sport equipment is an example of reciprocal support on the physical level, people also witnessed support on the emotional level. Participant Anu recalled that encouragement was given to the athletes by other participants or spectators throughout the race, as "people came out of their houses and shouted: 'Ah, run, you can do it!' And at working places they stopped their work and shouted, cheering up, running behind us with water... so they were very helpful."

Other respondents highlighted positive intergroup interaction and active support after the race, when the sportspeople came together, celebrated, and relaxed at the finish line. Matt, a local attendee from Colombo, stated that "irrespective of their ethnic backgrounds, people were given massages and physical treatment at the finish line." Andy summed up that it was great to experience that "we [the Sinhalese] can get something from them, and they [the Tamils] can get something from us also!"

Contact and Networks. The category of Contacts and Networks includes elements of establishing and advancing individual contacts and friendships; increasing intergroup contacts and bridging; and establishing business relationships. 
The IR4P contributed to establishing individual contacts and friendships among participants, spectators, and organizers. Interview respondents described the sport event as an opportunity to get in touch with other people from their own ethnic group and with individuals from other ethnic backgrounds. Shanto, a member of the Sinhalese Nattandiya community, reported that "after the Run for Peace I also met up with some new Muslim friends from MTV and Red Bull, from Lotteries Board and I am still friends with them. They are coming to our parties and they are good friends for always." The sport event further offered "the chance to interact with foreigners from the US, Europe, Australia, and other parts of Asia," which represents an opportunity for extending contacts to the international level. The international participants and volunteers agreed by saying that the sport event contributed to "forming new social relationships. We won a lot of contacts in Sri Lanka while working at this event. Actually, we won a lot of friends."

In addition to the newly established intragroup and intergroup contacts, the IR4P allowed for professional contacts to be developed. Mark said that for individuals, particularly those from the organizing committee, it was the chance to "make important business contacts with ... the Sri Lankan organizers, the Sri Lankan sponsors, the Sri Lankan people from the Ministries, [who] were all involved in the organizing of the event." Overall, contacts, friendships, and networks were valued as a vital part in the intra- and intercommunity development process: on the interpersonal, intragroup, and intergroup levels.

Learning and Development. The category of Learning and Development includes the development of specific sport and management skills; intercultural learning; and the expansion of cultural perspectives. The IR4P allowed people to gain a better understanding of each other and to learn that togetherness is possible and indeed beneficial within a noncompetitive leisure environment. Kevin from the Ministry of Sports believed that members of the local communities learned valuable social skills, and gained professional knowledge from partaking in the planning, management, and implementation phases. As he explained:
Learning means sometimes the organization of the race. So different parts of the day: that the transport things are there, the food is there, accommodation is there, the media part is there. So when someone organizes this type of event, these things are to be considered. So actually we got a lot of outcome from this one event, regarding the things we must think of all the time. That's right. So myself and my officers also, they got a lot of experience from this race. So next time we are doing this, we have the knowledge.

Kevin's comment suggests that the local communities will benefit from the increase in knowledge when organizing future activities and sport events.

\section{Negative Sociocultural Experiences}

Attitudes. Around the event, differences in attitudes towards the organizers, participants, and spectators could be observed. People showed varying levels of enthusiasm and engagement in regards to the events and the "Games for Peace" theme. For example, onlookers from the local community, who were not directly involved in the sport event, disturbed participants and were described as not having the best intentions. Sinhalese IR4P participant Anu observed: "I could see from their behavior and the way that they were talking that they were not really for the program. Some were coming to see girls; some were coming just to laugh at the [participants]."

Anu went on to describe these spectators as "disturbing intruders," who did not share the spirit of the event but intimidated participants. This comment highlights an issue that open intercommunity sport events contain risks of behavior that is not conducive to positive social outcomes.

Further illustrations of this theme of Attitudes related to the welcome speeches given at the opening of the IR4P event. While most participants, spectators, and volunteers actively "lived" a peaceful togetherness and encouraged others to interact and participate, the chief guests only went as far as "doing their job" and were not seen to contribute greatly to the broader social development objectives of the event. Sudu, a Sinhalese community member from Marawila, was not impressed with the style of the speech given by the Sinhalese chief guest, saying that "some words 
that he used to introduce these Muslim people were words that were really not matching. It wasn't only negative... I also felt that he was also not civilized, so not very polite." Sudu's comment shows that she did not feel her community was being represented appropriately by the chief guest.

Management Tensions. This category includes communication problems and management issues resulting in a smaller than expected number of participants at the sport event and the after party. Mark, a member of the IR4P organizing team, argued that communication issues were prevailing in the lead-up phase of the sport event. The organizing group became frustrated with certain stakeholders, who did not provide sufficient input and did not communicate properly and inclusively:

I wished that [the Ministry of Sports] would have told us more about their decisions and what they were thinking. When we had meetings with the Ministry we were basically always telling what we were thinking and how we would like to do that and they approved it or not. But they never really told us what they wanted to do with this event, what it meant to them. So that was in my eyes clearly a problem.

While Mark wished for more input and communiqué from the Sports Ministry, he also acknowledged that communication issues may have originated from uncertainty or a lack of understanding in the values and goals of the sport event. He went on to say:

We thought they knew what we wanted to do with this event. But we didn't explain well enough what our goals and objectives were. [Probably] they saw it as just another sport event and did not put as much heart into it as we did.

Poor communication and cooperation between organizers and stakeholders in the lead-up phases of the sport event led to a decrease in overall registration numbers. Many people who had been involved in the 2004 National Run for Peace in Kandy "noticed that this year participation was low, which was a bit disappointing" and that valuable opportunities for maximizing sport event benefits were lost. Marco, on the other hand, believed that "transportation and logistical problems" were to blame for the lower than expected participant numbers. He suggested that traveling to Colombo was a hindering factor particularly for the Tamil and Muslim communities from the northeastern parts of the island. Arguably, the 2004 event in Kandy attracted more participants as access for the Muslim and Tamil communities was easier and more comfortable, due to smaller travel distances and less Governmental restrictions.

Another managerial issue was mentioned by Shanto, who observed that fewer than expected local participants and spectators attended the sport event after party:

There were a lot of people participating in the marathon, but after they were running, after they got their certificates and got their prizes, they vanished. Now this is not a complaint but a thing missing: only the A.G.S.E.P. staff and the Peace Village staff were at the music show. [We need better] organization and planning to include ALL people. We must inform [everyone], and if they support the marathon, they should be at the party also, because it was for them!

Shanto's comments do not explain the reasons as to why he believed local participation was low, but differences in sociocultural values may have contributed to the disappointing attendance of locals at the after party. The organizers explained that modern Western style attire, music, and dancing were dominant, and that alcohol was readily available. These elements may have affected people's decision to attend the party.

\section{Discussion}

The aim of this research was to empirically test whether the IR4P as an intercommunity sport event could provide positive sociocultural experiences on a practical level, while enhancing intergroup relations and stocks of social capital between disparate Sinhalese, Tamil, and Muslim communities in Sri Lanka. Seven broad themes emerged from the study, representing both positive and negative sociocultural experiences (see Table 2).

Five themes were seen to contribute to an increase in the stock of social capital and a reduction of social barriers, which play a role in enhancing intergroup relations. First, the IR4P provided par- 
ticipants and their communities with important opportunities for socializing, as opposed to a passive spectator experience of elite performance and symbolic representations of social interaction. Socializing within and between groups was enabled through the active participation encouraged by A.G.S.E.P. around the sport event-an inclusive development approach conducive to intergroup development (Atkinson, 1991; Schulenkorf, 2010a; United Nations, 2006). These active participatory opportunities reduced the distance between people and groups; further, they allowed people to a) share the experience of a sport event with others, b) contribute to the innovative idea of peace building through sport events, and c) celebrate with newly made friends at the after-party.

Second, also contributing to a supportive environment capable of building social capital is the notion that the IR4P was identified as a neutral space for participation. As such, the sport event was seen as a promising starting point for the creation of trust with an intrinsic power for removing barriers between people, groups, and institutions (see Brown et al., 2003). Respondents argued that the impartiality of A.G.S.E.P., the official support from all communities, police presence, and the social peace theme contributed to feelings of safety, comfort, and inclusiveness among participating groups. The neutrality component of sport events had been outlined in the literature as an important opportunity to place diverse groups on a level playing field where relationships and trust can develop. This study confirms this argument and findings link to the three types of trust Putnam (1993, 2000, 2003) claims are a central part of social capital: personalized trust, generalized trust, and institutional trust. This suggests that carefully planned intercommunity sport events can provide a vehicle for both bonding and bridging social capital, even in divided societies.

A third element of social capital is reciprocity (Putnam, 1993, 2000; Stone, 2001), which was demonstrated in this study through the active engagement for physical and emotional support for others. On a physical level, some well-off people provided the poorer ones with sport equipment such as running shoes and clothing, while on an emotional level, participants were continuously encouraged and cheered on by local residents dur- ing the race in Colombo. The IR4P encouraged people to help others in need, which shows that around sport events reciprocal exchanges and solidarity are possible even among members of disparate communities. These findings add to Yuen's (2005) results from her study on an international sport camp, which showed that leisure activities can foster reciprocal support in social learning and skill development.

Fourth, the sport event facilitated contact within groups and opportunities to establish networks $b e$ tween groups, which suggest that new relationships were formed on the intragroup and intergroup levels. In fact, links were also created on the institutional level, as members of the organizing team benefited from improved business contacts and the creation of professional networks. This indicates that the sport event contributed to the bonding, bridging, and linking elements indicative of social capital building (Putnam, 2000; Woolcock, 2001).

It is argued that the active engagement of participants and organizers at the community level provided a vehicle and catalyst to such an effective development of social capital within an intensely short sport event life cycle. While previous studies have shown that cultural events and festivals can establish contacts and facilitate networks within communities (Reid, 2006; Small, 2007), this study found that a noncompetitive sport environment allows for networking and relationship building even among members of groups that are engaged in a quasi civil war.

Fifth, learning and development plays a critical role in the intercommunity sport event context and is considered to operate at two levels. First, cooperation between the communities and A.G.S.E.P. provided locals with opportunities to participate with and learn from others in a culturally diverse environment. Community members who were involved in the organization and design of the sport event had the chance to expand their horizons, as they were able to learn management skills through working alongside A.G.S.E.P. Second, it was found that they had the opportunity to shape and develop the sport event program as a culturally diverse team, a learning process that built bridges between people and groups (see Auld \& Case, 1997; Brown et al., 2003). Respondents revealed 
that intercultural learning contributed to intergroup understanding and respect.

While the five themes previously discussed have been shown to make positive contributions to social capital stocks and the break-down of social barriers, it must also be recognized that intercommunity sport events such as the IR4P can be subject to negative influences, which may create negative outcomes for participating groups. First, differences in attitudes and social behavior may occur inside and outside the sport event environment; for example, by inapt manners shown by community members towards "others" at the sport events. Respondents revealed that some people who were not directly involved in the sport event made negative comments about the event organizers and active participants. This suggests that parts of the community did not accept the idea of intercommunity celebration, or perhaps rejected the idea of a Western change agent organizing sport events in the Global South (see, e.g., Guest, 2009). In some cases, locals intimidated participants and spectators with words and gestures, which highlights the potential of a sport event to reduce the stock of social capital through eroding the sense of safety, comfort, and trust, which is considered so important to facilitating social capital building (Putnam, 1993, 2000).

Second, communication problems and cultural differences were identified as the main reasons for management tensions. Respondents revealed that when interacting with people from ethnically diverse groups, a different interpretation of values occurred. There were examples where differences in enthusiasm for the event's ideals and a lack of respect towards "others" led to disagreement and tensions between groups. For example, the dedicated peace activists were left frustrated with participants and stakeholders who focused predominantly on the physical sport aspect of the event. Furthermore, respondents observed that the afterparty was dominated by international participants, volunteers, and tourists, which left both the organizers and attendees disappointed. It was found that the timing and location of the sport event and after-party sites presented great challenges for the participating communities. As a consequence, many locals were unable or unwilling to participate in the sport event, which reduced opportuni- ties to advance both bonding and bridging social capital. This example highlights the importance of including the communities' voices in the strategic event management process to cater for local demands (see Getz \& Frisby, 1988; Kelly, 2002; Schulenkorf, 2010a).

This research has a number of implications for the planning and management of future intercommunity sport events that aim to improve intergroup relations and contribute to social capital building in divided societies. It was demonstrated that opportunities for socializing and establishing contacts and networks exist before, during, and after the event. Before the event, they come in the form of positions on the organizing committee, where event organizers are encouraged to provide opportunities for local participation; during the event they come in the form of volunteering, attending, or participating in sporting activities; and after the event they come from contributions and involvement in follow-up projects. In all three instances, social capital can be created and advanced through bonding with like-minded individuals from people's own social group and bridging with people from other communities. To have lasting value, the new networks need to be sustained beyond the first contact, and strategies for follow-up events and community celebrations should be put in place by empowered communities and supportive event organizers.

Importantly, a "level playing field" or "neutral space" for interaction needs to be provided by impartial event organizers, and people from all different ethnic and socioeconomic backgrounds should be encouraged to participate and share experiences as a team. The focus of intercommunity events should be on the social and leisure experiences while competition should not be emphasized to avoid the reemergence of rivalries. Furthermore, organizers have to be aware of the potential negative impacts and limits of peace events and prepare locals for differences in community attitudes. Some people may not be open to sport as a means or vehicle for integration, and others may simply refuse to reconcile after years of sociopolitical tensions. Overall, while intercommunity sport events should be encouraged and expanded as valuable opportunities for social capital building, they cannot be regarded and promoted as a panacea for all 
problems between disparate communities in divided societies.

\section{Conclusion}

Sport and sport events have been criticized for their lack of rigorous empirical evaluation and the reliance on subjective experiences and anecdotes suggesting that they can contribute to intergroup development and social cohesion (Chalip, 2006; Lea-Howarth, 2006). Therefore, this article presented an in-depth investigation of the 1st International Run for Peace and its contribution to constructing dialogue and creating social capital between disparate communities in the ethnically divided Sri Lanka. It was found that intercommunity sport events can provide spectacle and color for participants and attendees, which may result in opportunities for socializing and intergroup celebration; an increase in trust; positive experiences of reciprocity and solidarity; opportunities to advance contacts and networks; and intercultural learning and development. Such positive experiences contribute to an increase in the stock of social capital available to participating communities. However, sport event managers and communities need to be aware of differences in attitudes among the organizers, participants, and various stakeholders, as well as different types of managerial tensions which may undermine the creation of social capital.

Overall, this study shows that as an active and participatory form of social development, intercommunity sport events offer potential to go beyond the symbolic value of spectator sport events and encourage people to experience firsthand the social power of intergroup celebration. While intercommunity sport events should be encouraged and expanded as part of an active social development process, it is too much to expect sport events to have a major impact on overall intergroup relations in the absence of a political settlement in divided societies. However, when integrated within a larger agenda of social, educational, and political support and inclusive reforms, they can make a modest contribution to bridging divides between disparate communities.

It can be concluded that if carefully planned and managed in accordance with local demands, sport events can be a starting point, a vehicle, a booster, and a catalyst for social capital. Future research should build on these findings and focus on developing strategies to sustain and grow relationships and social capital beyond the sport event lifecycle, and to leverage positive experiences to the wider community.

\section{References}

Asian German Sports Exchange Program. (2005). A.G.S.E.P. profile. Retrieved May 10, 2006, from http://www.agsep. com/page.php?id=157

Armstrong, G. (2004). Life, death, and the biscuit: Football and the embodiment of society in Liberia. In G. Armstrong \& R. Giulianotti (Eds.), Football in Africa. Conflict, conciliation, and community (pp. 183-209), Hampshire: Palgrave

Armstrong, G., \& Giulianotti, R. (2001). Fear and loathing in world football. Oxford/New York: Berg.

Atkinson, J. (1991). Recreation in the Aboriginal соттиnity; A report to the department of the arts, sport, environment, tourism, and territories. Canberra: Australian Government Publishing Service.

Auld, C. J., \& Case, A. J. (1997). Social exchange processes in leisure and non-leisure settings: A Review and exploratory investigation. Journal of Leisure Research, 29(2), 183-200.

Australian Bureau of Statistics. (2002). Measuring social capital: Discussion summary and next steps. Australia: Author.

Bairner, A., \& Darby, P. (2000). Divided sport in a divided society: Northern Ireland. In J. Sugden \& A. Bairner (Eds.), Sport in divided societies (pp. 51-72), Oxford: Meyer \& Meyer (UK) Ltd.

Beazley, P., \& Richards, L. (2000). The NVivo Qualitative Project Book. London: Sage Publications.

Bilger, A. (Juni 2006). Kriegsangst im Urlaubsparadies. Der Spiegel Online. Retrieved from http://www.spiegel. de/politik/ausland/0,1518,421813,00. $\overline{\mathrm{html}}$

Bishop, H., \& Jaworski, A. (2003). "We beat 'em:" Nationalism and the hegemony of homogeneity in the British press reportage of Germany versus England during Euro 2000. Discourse and Society, 14, 243-271.

Brown, K. T., Brown, T. N., Jackson, J. S., Sellers, R. M., \& Manuel, W. J. (2003). Teammates on and off the field? Contact with black teammates and the racial attitudes of white student athletes. Journal of Applied Social Psychology, 33(7), 1379-1403.

Chalip, L. (2006). Towards social leverage of sport events. Journal of Sport and Tourism, 11(2), 109-127.

Coalter, F. (2007). A wider social role for sport: Who's keeping the score. Abingdon, Oxon: Routledge.

Croft, S. (2005). South Asia's arms control process: Cricket diplomacy and the composite dialogue. International Affairs, 81(5), 1039-1060. 
Crotty, M. (1998). The foundations of social research. St. Leonards, Sydney: Allen \& Unwin.

Denzin, N. K., \& Lincoln, Y. S. (2005). The SAGE handbook of qualitative research ( $3 \mathrm{rd}$ ed.). Thousand Oaks, CA: Sage Publications.

Dimeo, P. (2001). "Team loyalty splits the city into two:" Football, ethnicity, and rivalry in Calcutta. In G. Armstrong \& R. Giulianotti (Eds.), Fear and loathing in world football (pp. 105-118) Oxford, UK: Berg.

Dimeo, P., \& Kay, J. (2004). Major sports events, image projection, and the problems of "semi periphery:" A case study of the 1996 South Asia Cricket World Cup. The World Quarterly, 25(7), 1263-1276.

Dunung, S. (1995). Doing business in Asia. New York: Lexington Books.

Dyreson, M. (2003). Globalizing the Nation-making process: Modern sport in world history. The International Journal of the History of Sport, 20(1), 91-106.

Fukuyama, F. (1995). Trust: The social virtues and the creation of prosperity. New York: The Free Press.

Gasser, P. K., \& Levinsen, A. (2004). Breaking post-war ice: Open fun football schools in Bosnia and Herzegovina. Sport in Society, 7(3), 457-472.

Gasser, P. K., \& Levinsen, A. (2006). Breaking post-war ice: Open fun football schools in Bosnia and Herzegovina. In R. Giulianotti \& D. Mcardle (Eds.), Sport in the global society. Special issue: Sport, civil liberties and human rights (pp. 165-180). New York: Routledge.

Getz, D., \& Frisby, W. (1988). Evaluating management effectiveness in community-run festivals. Journal of Travel Research, 27(1), 22-27.

Glesne, C. (1999). Meeting qualitative inquiry. In C. Glesne \& A. Peshkin (Eds.), Becoming qualitative researchers: An introduction (2nd ed., pp. 1-17), New York: Longman.

Griggs, G. (2004). Soccer hooliganism in England between the wars. The Sport Journal, 7(3).

Guelke, A., \& Sugden, J. (2000). Sport and the "normalizing" of the new South Africa. In J. Sugden \& A. Bairner (Eds.), Sport in divided societies (pp. 73-96), Oxford: Meyer \& Meyer (UK) Ltd.

Guest, A. M. (2009). The diffusion of developmentthrough-sport: Analyzing the history and practice of the Olympic movement's grassroots outreach to Africa. Sport in Society: Cultures, Commerce, Media, Politics, 12(10), 1336-1352.

Hall, C. M., Selwood, J., \& McKewon, E. (1995). Hedonists, ladies, and larrikins: Crime, prostitution, and the 1987 America's Cup. Visions in Leisure and Business, 14(3), 28-51.

Hargreaves, J. (2000). Heroines of sport: The politics of difference and identity. London/New York: Routledge.

Hay, R. (2001). "Those bloody Croatians:” Croatian soccer teams, ethnicity, and violence in Australia, 1950-99. In G. Armstrong \& R. Giulianotti (Eds.), Fear and loathing in world football (pp. 77-90), Oxford, UK: Berg.

Higham, J. (1999). Commentary-Sport as an avenue of tourism development: An analysis of the positive and negative impacts of sport tourism. Current Issues in Tourism, 2(1), 82-90.

Hoepfl, M. C. (1997). Choosing qualitative research: A primer for technology education researchers. Journal of Technology Education, 9(1), 47-63.

Höglund, K., \& Sundberg, R. (2008). Reconciliation through sports? The case of South Africa. Third World Quarterly, 29(4), 805-818.

Ingham, A. G., \& McDonald, G. (2003). Sport and community/communitas. In R. C. Wilcox, D. L. Andrews, R. Pitter, \& R. L. Irwin (Eds.), Sport dystopias: The making and meanings of urban sport cultures (pp. 17-33), Albany, NY: State University of New York Press.

Jarvie, G. (2003). Internationalism and sport in the making of nations. Identities: Global studies in Culture and Power, 10, 537-551.

Jarvie, G., \& Reid, A. (1999). Sport, nationalism, and culture in Scotland. The Sports Historian, 19(1), 97-124.

Kellett, P., Hede, A.-M., \& Chalip, L. (2008). Social policy for sport events: Leveraging (relationships with) teams from other nations for community benefit. European Sport Management Quarterly, 8(2), 101-122.

Kelly, I. (2002). Peace through events: A SWOT analysis. In L. Jago, M. Deery, R. Harris, A.-M. Hede, \& J. Allen (Eds.), Events and place Mmking (pp. 8-28). Sydney: Australian Centre for Event Management.

Kilpatrick, S., Bell, R., \& Falk, I. (1999). The role of group learning in building social capital. Journal of Vocational Education and Training, 51(1), 129-144.

Lawson, H. A. (2005). Empowering people, facilitating community development, and contributing to sustainable development: The social work of sport, exercise, and physical education programs. Sport, Education, and Society, 10(1), 135-160.

Lea-Howarth, J. (2006). Sport and conflict: Is football an appropriate tool to utilize in conflict resolution, reconciliation, or reconstruction? MA thesis, University of Sussex, Sussex.

Maguire, J. A. (2002). Sport worlds: A sociological perspective. Champaign, IL: Human Kinetics.

Midgley, J. (1986). Community participation, social development, and the state. New York: Methuen.

Minichiello, V., Aroni, R., Timewell, E., \& Alexander, L. (1995). In-depth interviewing: Principles, techniques, analysis (2nd ed.). Kings Gardens, Melbourne: Longman.

Misener, L., \& Mason, D. S. (2006). Creating community networks: Can sporting events offer meaningful sources of social capital? Managing Leisure, 11(1), 39-56.

Müller, N., \& Gerling, J. (2006). The idea of peace as Coubertin's vision for the modern Olympic movement: Development and pedagogic consequences. The Sport Journal, 9(1).

Myers, M. D. (1997). Qualitative research in information systems. MIS Quarterly, 21(2), 241-242.

Nauright, J. (1997). Sport, cultures, and identities in South Africa. London/Washington: Leicester University Press. Neuman, W. L. (2003). Social research methods: Qualita- 
tive and quantitative approaches (5th ed.). Boston/London: Allyn and Bacon.

Nicholson, M., \& Hoye, R. (2008). Sport and social capital. Oxford: Butterworth-Heinemann.

Ohmann, S., Jones, I., \& Wilkes, K. (2006). The perceived social impacts of the 2006 Football World Cup on $\mathrm{Mu}-$ nich residents. Journal of Sport and Tourism, 11(2), 129-152.

Putnam, R. D. (1993). Making democracy work: Civic traditions in modern Italy. Princeton, NJ: Princeton University Press.

Putnam, R. D. (2000). Bowling alone: The collapse and revival of American community. New York: Simon \& Schuster.

Putnam, R. D. (2003). Better together: Restoring the American community. New York: Simon \& Schuster.

Quinn, J. (1999). Where need meets opportunity: Youth development programs for early teens. The Future of Children WHEN SCHOOL IS OUT, 9(2), 96-116.

Reid, S. (2006). The social consequences of community events in rural areas: A stakeholder perspective. Ph.D. thesis, University of Queensland, Brisbane.

Sack, A. L., \& Suster, Z. (2000). Soccer and Croatian nationalism: A prelude to war. Journal of Sport and Social Issues, 24(3), 305-320.

Schulenkorf, N. (2009). An ex ante framework for the strategic study of social utility of sport events. Tourism and Hospitality Research, 9(2), 120-131.

Schulenkorf, N. (2010a). The roles and responsibilities of a change agent in sport event development projects. Sport Management Review, 13(2), 118-128.

Schulenkorf, N. (2010b). Sport events and ethnic reconciliation: Attempting to create social change between Sinhalese, Tamil, and Muslim sportspeople in war-torn Sri Lanka. International Review for the Sociology of Sport, 45, 273-294.

Skinner, J., Zakus, D., \& Cowell, J. (2008). Development through sport: Building social capital in disadvantaged communities. Sport Management Review, 11(3), 253275.

Small, K. (2007). Understanding the social impacts of festivals on communities. Ph.D. thesis, University of Western Sydney, Sydney.

Smith-Spark, L. (2006, June 12). Joy and pain for World Cup fans. BBC News. Retrieved from http://news.bbc. co.uk/2/hi/asia-pacific/5073832.stm

Smith, J. M., \& Ingham, A. G. (2003). On the waterfront: Retrospectives on the relationship between sport and communities. Sociology of Sport Journal, 20(3), 252274.
Soutar, G. N., \& McLeod, P. B. (1993). Residents' perceptions on impact of the America's Cup. Annals of Tourism Research, 20, 571-582.

Stidder, G., \& Haasner, A. (2007). Developing outdoor and adventurous activities for coexistence and reconciliation in Israel: An Anglo-German approach. Journal of Adventure Education and Outdoor Learning, 7(2), 131140.

Stone, W. (2001). Measuring social capital: Towards a theoretically informed measurement framework for researching social capital in family and community life. Melbourne: Australian Institute of Family Studies.

Sugden, J. (1991). Belfast united: Encouraging cross-community relations though sport in Northern Ireland. Journal of Sport and Social Issues, 15(1), 59-80.

Sugden, J. (2006). Teaching and playing sport for conflict resolution and co-existence in Israel. International Review for the Sociology of Sport, 41(2), 221-240.

Thomas, D. R., \& Dyall, L. (1999). Culture, ethnicity, and sport management: A New Zealand perspective. Sport Management Review, 2(2), 115-132.

Thomson, A., Darcy, S., \& Pearce, S. (2010). Ganma theory and third-sector sport-development programs for Aboriginal and Torres Strait Islander youth: Implications for sports management. Sport Management Review, 13(4), 313-330.

Torkildsen, G. (2000). Leisure and recreation management (4th ed.). New York: Taylor \& Francis.

United Nations. (2006). Sport for development and peace: The way forward: Sixty-first session, Agenda item 49, A/61/373, United Nations General Assembly.

Vinoker, M. B. (1988). More than a game-sports and politics. New York: Greenwood.

Willis, K. (2006). Analyzing qualitative data. In M. Walter (Ed.), Social research methods: An Australian perspective (pp. 257-279). South Melbourne: Oxford University Press.

Woolcock, M. (2001). Social capital, civic society, and poverty reduction: Arrangements, disagreements, tensions. Address to ANU Staff Association, Canberra.

Yuen, F. C. (2005). Building community and social capital through children's leisure in the context of an international camp. In T. A. Delamere, C. Randall, \& D. Robinson (Eds.), Eleventh Canadian Congress on Leisure Research (pp. 1-6). Nanaimo, BC: Department of Recreation and Tourism Management Malaspina University-College. 